\title{
Design of the Wireless Power Supply System for the Wheel Force Sensor
}

\author{
Yongjin Kwon, Kyuwon Jeong \\ Dept. of Mech. Eng., Chungbuk National University \\ 1 Chungdae-ro, Seowon-gu, Cheongju-si, Chungbuk, Korea \\ nongjin@naver.com; jeong@ chungbuk.ac.kr
}

\section{Extended Abstract}

A vehicle consists of many components such as chassis, engine, brake and steering system. While a vehicle is running, three axial forces and three moments are produced by interaction between the wheel and the ground. It is quite important to measure exactly those forces to improve the performance of the vehicle.

Generally, a load cell is used for measuring force. But conventional load cell used in weighing scale is operated in static conditions. In this research, in order to measure three axial forces and moments at dynamic condition such as a car is running, we designed a new type wheel force sensor. The wheel force sensor is a kind of multi-axis load cell. It has a diskshaped body which consists of six sensing units [1-4].

To apply this wheel force sensor to a running vehicle, a wireless type signal processing circuit is studied in this research [5-6]. The circuit is operated by the wireless power supply system. The power supply system consists of a resonant converter, a primary coil, a secondary coil and a rectifier circuit. The transmitting unit which consists of a resonant converter and a primary coil makes a magnetic field. Then the receiving unit which consists of a secondary coil and a rectifier circuit connects on the magnetic field [7]. And a rectifier circuit converts the AC voltage to DC voltage to enable to use at the wireless type signal processing circuit. The efficiency of the power supply system and the stability are affected by the combination of two coils and the frequency of the input voltage, because the power supply system is unstable when the frequency is unsuitable to system.

This paper is about improving the efficiency of the wireless power supply system. Many different kinds of coils are tested, and we found a combination of coils which is ideal to improve the power supply system efficiently. Also we found the frequency of input voltage which is optimal to stabilize the power supply system of input voltage through a number of experiments.

\section{References}

[1] H. Youshikawa and Kakogawa, "Device for measuring components of force and moment applied to vehicle tire," U.S. Patent 4748 844, June 7, 1988.

[2] K. Ono, and Y. Hatamura, "A new Design for 6-component Force/Torque Sensors," Mechanical Problems in Measuring Force and Mass., pp. 39-48, 1986.

[3] A. Yabuki, "Six-Axis Force/Troque Sensor for Assembly Robots," FUJITSU Sci. Tech. J., vol. 26, no. 1, pp. 41-47, 1990.

[4] M. G. Kim and J. W. Joo, "Structural design and evaluation of six-component wheel dynamometer," Journal of The Korea Society of Mechanical Engineers, vol. 40, no. 1, pp. 53-63, 2016.

[5] S. H. Kim, "ZigBee service gateway enabling dynamic reconfiguration," The Journal of the KICS, vol. 32, no. 10B, pp. 644-654, 2007.

[6] H. H. Choi, "A transmission time allocation Scheme in ZigBee Network," Journal of the Korea society of computer and information, vol. 16, no. 4, pp. 119-126, 2011.

[7] J. S. Kim, "A Study of low power wireless energy trasfer circuit by using non-contact," Department of Electric and Electronic Engineering, Semyung Univ. Jecheon, Korea, 2013. 